\title{
Risk of antibiotic resistant meningococcal infections in Hajj pilgrims
}

\author{
Have a high index of suspicion if people fall ill on returning home
}

\author{
Alimuddin Zumla professor ${ }^{1}$, Ziad A Memish professor ${ }^{2}$ \\ ${ }^{1}$ Centre for Clinical Microbiology, Division of Infection and Immunity, University College London, London, UK; ${ }^{2}$ Infectious Diseases Division, Department \\ of Medicine and Department of Research, Prince Mohamed Bin Abdulaziz Hospital, Riyadh, Saudi Arabia
}

On 22 July Public Health England issued an important public health announcement - the unusual occurrence in the UK of three people with non-groupable meningococcal infections connected with recent travel to Mecca, Saudi Arabia. ${ }^{1}$ Two presented with conjunctivitis just days after returning from a pilgrimage. The third person, who was a close contact of one case but had not travelled to Mecca, developed invasive meningococcal disease. ${ }^{1}$ Neisseria meningitidis isolates from all three individuals had the same phenotype (NG;NT;P1.15); they were resistant to ciprofloxacin and had only intermediate susceptibility to penicillin. Meningococcal conjunctivitis is known to carry a high risk of invasive disease $\mathrm{e}^{1-3}$ and requires immediate treatment, along with antibiotic prophylaxis for close contacts.

Ciprofloxacin is the recommended chemoprophylaxis in both the UK and Saudi Arabia. The identification of resistant meningococcal conjunctivitis in people returning from Mecca, highlights the urgent need to review currently recommended prophylactic measures for Hajj pilgrims, how best to prevent spread of $N$ meningitidis between people attending mass gatherings, and how to protect contacts on return. ${ }^{4-6}$

Over 2.2 million pilgrims (25 000 from the UK) travelled from over 180 countries to Mecca, Saudi Arabia, for the 2019 Hajj pilgrimage, which took place from 9 August to 14 August. Pilgrims will make their way home over the next few weeks, and health services in destination countries need to be on heightened alert for imported pathogens with epidemic potential, including ciprofloxacillin resistant $N$ meningitidis. ${ }^{6}$ Continued global surveillance for meningococcal disease and antibiotic resistance, along with both epidemiological and molecular research are essential to improve case detection, predict trends, and inform evolving prevention and control strategies. ${ }^{5}$

\section{Prevention challenges}

The annual Hajj pilgrimage has been associated with repeated outbreaks of invasive meningococcal disease. The largest occurred in 1974 (2673 cases), 1988 (1618 cases), 2000 (338 cases), and 2001 (316 cases). ${ }^{7}$ Since 2001 the Saudi authorities have strictly enforced a visa requirement for pilgrims, mandating vaccination with a single dose quadrivalent meningococcal vaccine (A,C,W-135, and Y). Adherence is $98 \%$ and no further major outbreaks have occurred. ${ }^{8}$

However, meningococcal disease remains a priority public health threat at the Hajj because of the evolving nature of invasive disease, emergence of antibiotic resistance, diverse and varying geographical trends in serotypes other than A, C, W-135, and $\mathrm{Y}$, fluctuations in incidence, and shifts in serogroups and genotypes which may increase epidemic potential. ${ }^{5}$

Every year, the Saudi Ministry of Health updates immunisation and antibiotic prophylaxis requirements for pilgrims, and meningococcal vaccination remains compulsory. ${ }^{8}$ However, concerns have been raised about vaccine availability, and it has been suggested that adherence might have been compromised among pilgrims attending the 2019 Hajj. ${ }^{9}$ Furthermore, even vaccinated pilgrims remain susceptible to disease caused by serogroups $\mathrm{B}$ and $\mathrm{X}$, which are not covered by the quadrivalent vaccine. $^{10}$

The high risk of meningococcal meningitis outbreaks, increasing incidence of serogroup B disease, and emergence of serogroup $\mathrm{X}$ in the African meningitis belt, ${ }^{5}$ from which a large number of pilgrims originate, is of particular concern. The Saudi Ministry of Health therefore mandates ciprofloxacin prophylaxis for pilgrims from meningitis belt countries. ${ }^{8}$ Over the past decade, 1.5 million doses of prophylactic ciprofloxacin have been administered to pilgrims at port of entry, and this has probably contributed to the emergence of ciprofloxacin resistant $N$ meningitidis. ${ }^{11}$

Authors of a recent large study of Hajj pilgrims ${ }^{5}$ recommended reconsidering use of ciprofloxacin for prophylaxis and including serogroup B vaccines in pre-travel requirements since more than $60 \%$ of $N$ meningitidis isolates from participants were B type. The current preventive measures for Hajj and other mass gatherings ${ }^{12}$ require urgent review and should be regularly updated in accordance with changes in the epidemiology of 
meningococcal disease, including resistance, and the availability of new vaccines.

Meanwhile, as the 2.5 million pilgrims from the 2019 Hajj return home and an expected 7 million pilgrims travel to Saudi Arabia for the Umrah mini pilgrimage over the next 12 months, questions remain about how best to protect them and their contacts from meningococcal disease. There is no room for complacency. Measures should include proactive clinical surveillance, education of first contact health professionals on the importance of taking a travel history, and a high index of suspicion for meningococcal infection among pilgrims who become ill on return. Public Health England has alerted NHS professionals of this need and provided management guidelines. ${ }^{13}$ Health authorities should do the same in all 180 home countries for Hajj pilgrims.

Competing interests: The BMJ has judged that there are no disqualifying financial ties to commercial companies. The authors declare the following other interests: $A Z$ and $Z M$ have an interest in mass gatherings medicine. $A Z$ is a member of the PANDORA-ID-NET Consortium funded by Grant RIA2016E-1609 from the European and Developing Countries Clinical Trials Partnership (EDCTP2) programme and is in receipt of a National Institutes of Health Research senior investigator award. The BMJ policy on financial interests is here: https://www.bmj.com/sites/default/ files/attachments/resources/2016/03/16-current-bmj-education-coi-form.pdf. Provenance and peer review: Not commissioned; externally peer reviewed.

1 Public Health England. Ciprofloxacin resistant cases of non-groupable meningococcal infection connected to recent travel to Mecca. 2019. https://www.medwayccg.nhs.uk/
component/rsfiles/preview?path=GP\%2Bresources\%2B2019\%252FJuly\%252FBriefing\% 2Bnote\%2BNG\%2Bmecca\%2Bcases\%2BJuly\%2B2019\%2Bfinal.pdf

2 Poulos RG, Smedley EJ, Ferson MJ, Bolisetty S, Tapsall JW. Refining the public health response to primary meningococcal conjunctivitis. Commun Dis Intell $Q$ Rep 2002;26:592-5.12549532

3 Orden B, Martínez R, Millán R, Belloso M, Pérez N. Primary meningococcal conjunctivitis. Clin Microbiol Infect 2003;9:1245-7. 10.1111/j.1469-0691.2003.00799.x 14686993

4 Badahdah AM, Alfelali M, Alqahtani AS, Alsharif S, Barasheed O, Rashid HHajj Research Team. Mandatory meningococcal vaccine, and other recommended immunisations: Uptake, barriers, and facilitators among health care workers and trainees at Hajj. World J Clin Cases 2018;6:1128-35. 10.12998/wjcc.v6.116.1128 30613671

5 Acevedo R, Bai X, Borrow R, etal . The Global Meningococcal Initiative meeting on prevention of meningococcal disease worldwide: epidemiology, surveillance, hypervirulent strains, antibiotic resistance and high-risk populations. Expert Rev Vaccines 2019;18:15-30. strains, antibiotic resistance and high-risk population

6 Memish ZA, Steffen R, White P, etal . Mass gatherings medicine: public health issues arising from mass gathering religious and sporting events. Lancet 2019;393:2073-84. 10.1016/S0140-6736(19)30501-X 31106753

7 Memish Z, Al Hakeem R, Al Neel O, Danis K, Jasir A, Eibach D. Laboratory confirmed invasive meningococcal disease: effect of the Haji vaccination policy, Saudi Arabia, 1995 to 2011. Euro Surveill2013;18:20581. 10.2807/1560-7917.ES2013.18.37.20581 24079399

8 Saudi Ministry of Health. 2019 Hajj requirements.https://www.moh.gov.sa/en/Hajj/ HealthGuidelines/HealthGuidelinesDuringHaj//Pages/HealthRequirements.aspx

9 Ebrahim S, Assiri AM, Memish ZA. Meningitis vaccine shortage and the 2019 Hajj mass gathering: market dynamics and epidemic control. J Travel Med 2019;taz039; [Epub ahead of print]. 10.1093/jtm/taz039. 31094426

10 Wilder-Smith A. Meningococcal disease: risk for international travellers and vaccine strategies. Travel Med Infect Dis 2008;6:182-6. 10.1016/j.tmaid.2007.10.002 18571105

11 Memish ZA, Al-Tawfiq JA, Almasri M, etal . Neisseria meningitidis nasopharyngeal carriage during the Hajj: a cohort study evaluating the need for ciprofloxacin prophylaxis. Vaccine 2017;35:2473-8. 10.1016/j.vaccine.2017.03.027 28343777

12 Badahdah AM, Rashid H, Khatami A, Booy R. Meningococcal disease burden and transmission in crowded settings and mass gatherings other than Haij/Umrah: a systematic review. Vaccine 2018;36:4593-602. 10.1016/j.vaccine.2018.06.027 29961604

13 PHE. Guidance for public health management of meningococcal disease in the UK-updated August 2019. https://assets.publishing.service.gov.uk/government/uploads/ system/uploads/attachment_data/file/823096/PHE_meningo_disease_guidelines.pdf

Published by the BMJ Publishing Group Limited. For permission to use (where not already granted under a licence) please go to http://group.bmj.com/group/rights-licensing/ permissions 